\title{
Spontaneous Expulsion of Subconjunctival Cysticercus Cellulosae
}

\author{
Col Kailash Chand ${ }^{*}$ Lt Col SK Srivastava ${ }^{+}$
}

MJAFI 2006; 62 : 188-189

Key Words : Cysticercosis; Ocular cyst

\section{Introduction}

$\mathrm{H}^{2}$ uman tapeworm, also manifests in visceral and somatic forms. The encysted eggs of T. solium, after ingestion by man, invades wall of the small intestine and disseminate haematogenously to all the organs of the body to produce, cysticercosis [1]. Cysticerci can lodge in any part of ocular and extra ocular tissue, although ocular localization is not frequent. Its simultaneous association with involvement of brain parenchyma is very uncommon [2]. With CT scan, MRI and ultrasonography, the localization of suspected lesion is easier now. However the final diagnosis relies on histopathology and serology [3].

In subconjunctival cysticercosis (SCC), larva develops small translucent cyst and once it dies, inflammatory reaction is evoked which may lead to blindness [4]. SCC is one of the frequent manifestations in eye but spontaneous expulsion is rare. Only six cases have been reported in the literature since 1970 [5].

We report a case of SCC, which was expulsed from the conjunctiva during ophthalmic examination of the patient on the operation table.

\section{Case Report}

13 years old boy, reported to the eye OPD with a cystic swelling, redness and painful movements of left eye of four months duration. The swelling had gradually increased to attain the present size of $12 \times 10 \mathrm{~mm}$. On examination, the left eye showed a translucent, smooth surfaced thin walled cystic swelling with small pedicle on nasal side of left eye. It was apparently arising from conjunctiva, and had well defined posterior limit. The nearby area was erythematous with prominent blood vessels. Movements of the eye were full but slightly painful. Fundus examination revealed no abnormality. There was no lesion in the right eye and vision in both eyes was $6 / 6$. General and physical examination was inconclusive. There was no palpable subcutaneous nodule over the body surface. Routine laboratory investigations and radiograph of skull and orbit were within normal limits. The patient was taken up for surgical removal but the expulsion of the cyst occurred during examination on the operation table. Histopathology of the cyst was consistent with cysticercosis (Fig.1). The patient was put on tablet albendazol for 21 days. On review, the redness of eye had subsided and there was no evidence of recurrence. The patient was followed for about one year and he continued to remain asymptomatic. The ultrasonography could not localize similar lesion in other parts of the body. However, CECT and serological investigations could not be under taken.

\section{Discussion}

Ocular and extra ocular cysticercosis is world wide

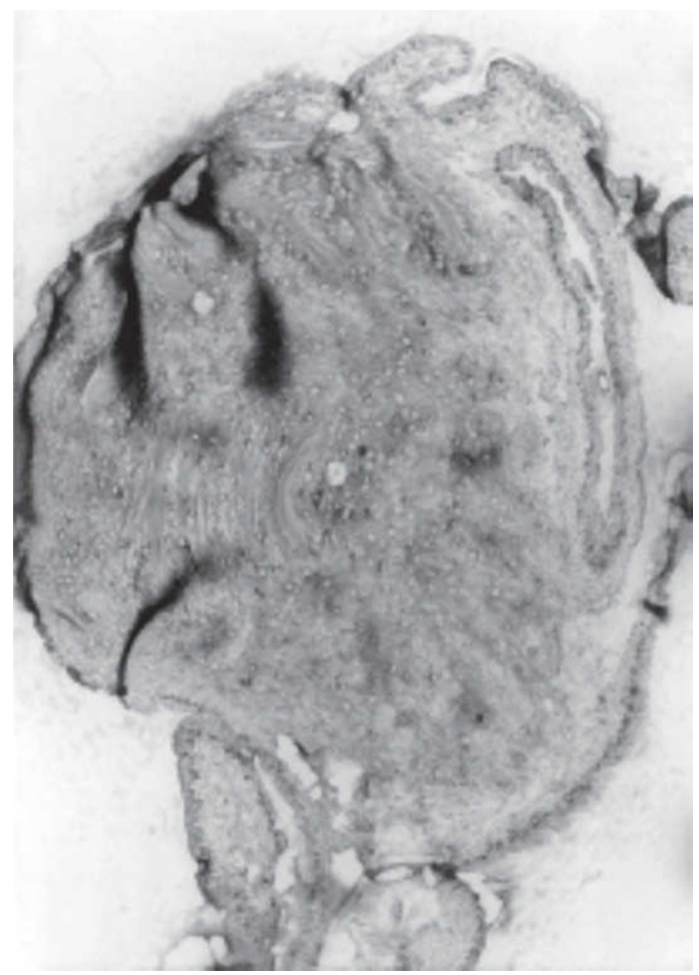

Fig. 1 : Microphotograph of subconjuctival cysticercosis cellulosae (x 100) 
in distribution and series of the cases have been reported from India [2-6]. The patients may be asymptomatic in early stage of the disease but it results in gradual loss of vision with or without pain, depending upon the location of the lodged larva. Vitreous and sub retinal space have been reported as the commonest site in the western literature but in India, sub conjunctiva has been the favorable site for the parasite [3,5]. Intra orbital and intra ocular cysticercosis are however uncommon as compared to involvement of neural and muscle tissue [1]. The commonest clinical presentation is subconjunctival cyst or proptosis in patients, mostly from poor socioeconomic status [2, 4]. In most studies higher incidence of orbital cysticercosis is reported in first two decades of life with male predominance $[3,6]$.

Spontaneous extrusion of SCC is uncommon and only a few cases have been reported in the literature out of which three were in a single study from India [5]. SCC is invariably attached with muscle sheath where inflammation is evoked. It is due to continuous friction that it finally pops out through conjunctiva by making hole, which heals in due course of time [4].

MRI is the best tool for the demonstration of cysticercosis. On ultrasound, the cyst is seen as a sonolucent area having well defined margins and with echodense center. It may show curvilinear highly reflective structures inside [4,6]. Medical and surgical treatment of ocular and extra ocular lesions depends upon the site but the results are not encouraging except where the cysts were easily accessible to surgery due to its superficial location [3]. Thorough evaluation of the orbit should be done in all the suspected cases of disseminated cysticercosis, before commencing medical treatment, to avoid ocular complications. Untreated cases of ocular cysticercosis may lead to blindness within 3-5 years.

\section{Conflicts of Interest}

None identified

\section{References}

1. Flisser A. Larval cestodes, In: Coiler L, Balows A, Sussman M, eds. Topey and Wilson's Microbiology and Microbial infection. $9^{\text {th }}$ ed. Parasitology (volume editors Cox FEG, Kreier JP, Walkelin D) Arnold UK. 1998; 5: 539-60.

2. Neelam Pushker, Mandeep S Bajaj, Mahesh Chandra and Neena. Ocular and orbital cysticercosis. Acta Ophthalmologica Scandinavica 2001; 79: 408.

3. Sarada David, Elizabeth Mathai. Ocular Cysticercosis-A Review of 25 cases. JAPI 2000; 48 (7): 704-7.

4. Sarita Magu, Manisha Nada, AK Khurana, JP Chugh. Spontaneous extrusion of subconjunctival cysticercus cellulosae. Br J Ophthalmol 2001; 85: 116-17.

5. Bansal RK, Gupta A, Grewal SPS, et al. Spontaneous extrusion of cysticercosis. Report of three cases. Ind J Ophthalmol 1992; 40: 59-60.

6. Reddy MCC, Gupta VP, Sarada P, Prabhakar V, Reddy DL, Anjanayulu C. Ocular cysticercosis- A case report of 15 cases. Ind J Ophthalmology 1980; 28: 89-92. 